\title{
Prevalence of Skin Reactions and Self-Reported Allergies in 5 Countries with Their Social Impact Measured through Quality of Life Impairment
}

\author{
Samir Salah ${ }^{1, *}$, Charles Taieb ${ }^{2}$, Anne' Laure Demessant ${ }^{1}$ and Marek Haftek ${ }^{3}$ \\ 1 La Roche-Posay Dermatological Laboratories, 92300 Levallois-Perret, France; \\ anne-laure.demessant@loreal.com \\ 2 European Market Maintenance Assessment, 94120 Fontenay-sous-Bois, France; charles.taieb@emma.clinic \\ 3 CNRS UMR5305, Tissue Biology and Therapeutic Engineering Laboratory, LBTI, 69367 Lyon, France; \\ marek.haftek@univ-lyon1.fr \\ * Correspondence: samir.salah@loreal.com; Tel.: +33-1-49-64-33-40
}

\section{check for} updates

Citation: Salah, S.; Taieb, C.; Demessant, A.L.; Haftek, M. Prevalence of Skin Reactions and Self-Reported Allergies in 5 Countries with Their Social Impact Measured through Quality of Life Impairment. Int. J. Environ. Res. Public Health 2021, 18, 4501. https://doi.org/10.3390/ ijerph18094501

Academic Editors:

Paul B. Tchounwou and Russell Hopp

Received: 5 February 2021

Accepted: 22 April 2021

Published: 23 April 2021

Publisher's Note: MDPI stays neutral with regard to jurisdictional claims in published maps and institutional affiliations.

Copyright: (c) 2021 by the authors. Licensee MDPI, Basel, Switzerland. This article is an open access article distributed under the terms and conditions of the Creative Commons Attribution (CC BY) license (https:// creativecommons.org/licenses/by/ $4.0 /)$.
Abstract: Background: The prevalence of allergies increases worldwide. Allergies may increase the risk of skin reactions. Objective: To evaluate the prevalence of allergies and skin reactions in the adult population, the strength of their relationship, and their impact on the quality of life Methods: An online survey was conducted in a representative population of 11,067 adults from China, USA, Brazil, Russia, and France. Results: Overall, 35.6\% of respondents reported having allergies, they were predominantly fair-skinned women, and younger than responders reporting no allergy. Among patients reporting allergies, 68.6\% declared that their allergy makes their skin reacts. A strong association between allergy and major skin reactions was observed, which were associated with skin discomforts such as itching, burning, and pain. Skin discomforts were associated with an increased risk of quality of life alteration. Conclusions: Quantifying the prevalence and the association of allergies with skin reactions and discomfort sensations is critical to evaluating the impact on quality of life. Since skin barrier alteration is hypothesized as a risk factor and a route of sensitization for allergy development, the daily use of topical treatments, such as moisturizers, could help prevent allergic skin reactions, discomfort and impaired quality of life in individuals with an altered skin barrier.

Keywords: allergies; skin manifestations; quality of life; skin barrier dysfunction; moisturizers

\section{Introduction}

The increasing occurrence of allergies, including food allergy, asthma, allergic rhinitis, has even been referred to as an "allergy epidemic", which is much observed in regions with rapid economic growth and massive urbanization [1-5].

Allergies may present with varied symptoms, including skin reactions such as urticaria, angioedema, atopic eczema, or contact dermatitis, as well as skin sensations, sometimes independent from the occurrence of skin lesions, such as pruritus, flushing, burning, and pain [6-8]. Skin reactions can have a substantial impact on the quality of life (QoL) of patients, which is a subjective status of wellbeing in the emotional, physical, social, and functional dimensions of an individual. The burden of disease, as a patient perceives it, is usually described by patients in terms of symptoms and impact on QoL [9-13]. It is, therefore, crucial to quantify the risk increase of skin reaction incidence in the presence of allergy.

Skin barrier impairment has been proposed as a risk factor and a route of sensitization for the development of food allergy and for the occurrence of allergic rhinitis and of allergic asthma $[14,15]$. Chemically or physically induced barrier dysfunction can be a cause of irritant or allergic contact dermatitis [16]. Indeed, inborn or acquired defects in skin barrier 
function, often associated with a chronic inflammatory reaction, may facilitate allergen entry and activation of immune priming, leading to local or systemic allergic responses.

The definition of precise causes of allergies often requires rigorous tests such as oral food challenge or patch testing performed by specialized healthcare professionals. This renders the prevalence of allergy in the general population difficult to estimate. Nevertheless, self-reported allergy prevalence represents an accessible means to assess and understand the burden of allergies.

So far, little is known about the strength of the relationship between allergy and skin reactions and associated discomfort sensations which ultimately generate a social burden that we can measure through quality of life impairment. Here, the data of an online survey assessing the prevalence of self-reported allergy and skin conditions, in the adult population in five countries: China, USA, Brazil, Russia, and France are reported.

\section{Materials and Methods}

\subsection{Study Population}

This online survey was conducted between December 2018 and January 2019 by a research house (HC Conseil Paris, Paris, France) using a quota sampling method for each country (sex, age, socio-professional status, and regional distribution). A total sample of 11,067 adult individuals was recruited, constituted of 2036 French, 2008 US Americans, 2010 Russians, 3010 Chinese, and 2003 Brazilians.

\subsection{Survey}

In addition to sociodemographic data, the survey also collected data on skin characteristics, lifestyle, exposome, allergies, medical diagnosis, skin reactions, discomfort sensations, and therapeutic treatments. Unfortunately, the quality of life questionnaire was only administered on a subset of 206 French patients with a persistent cough. Therefore, the impact of skin discomfort in terms of risk increase on quality of life impairment will be evaluated only on this subset. See Supplementary Materials in S1 for questionnaire details.

\subsection{Statistical Analysis}

Comparison between participants who reported allergies and participants who did not report any allergy can be found in published studies [17-19]. Comparisons of incidences between groups through $2 \times 2$ contingency tables were performed using a Fisher's exact test. Relative risk (RR) was calculated and displayed as effect size metric. For $3 \times 3$ and more contingency tables, a Chi-square test was used. The statistical level of significance was set at $5 \%$. Statistical analyses were performed using the Python SciPy package (version 1.5.2., http:/ / www.scipy.org, accessed on 23 April 2021).

\section{Results}

\subsection{Demographic Description}

The characteristics of the populations with no allergy and with allergies are detailed in Table 1.

Table 1. Characteristics of the populations.

\begin{tabular}{cccc}
\hline & No Allergy & With Allergies & \\
\hline $\begin{array}{c}\text { Participants (\%) } \\
\text { Age }\end{array}$ & $7125(64.4 \%)$ & $3942(35.6 \%)$ & $<0.001$ \\
Mean (SD) & $41.5(14.7)$ & $39.83(14.1)$ & $<0.001$ \\
Gender & & & \\
Female & $3443(48.3 \%)$ & $2142(54.3 \%)$ & \\
Male & $3682(51.7 \%)$ & $1800(45.7 \%)$ & \\
\hline
\end{tabular}


Table 1. Cont.

\begin{tabular}{cccc}
\hline & No Allergy & With Allergies & \\
\hline Skin phototype * & & & $<0.001$ \\
I & $857(12.0 \%)$ & $587(14.9 \%)$ & \\
II & $1875(26.3 \%)$ & $1116(28.3 \%)$ & \\
III & $2741(38.5 \%)$ & $1331(33.8 \%)$ & \\
IV & $1134(15.9 \%)$ & $635(16.1 \%)$ & \\
V & $270(3.8 \%)$ & $147(3.7 \%)$ & \\
VI & $248(3.5 \%)$ & $126(3.2 \%)$ & \\
\hline
\end{tabular}

*: skin phototypes according to the Fitzpatrick classification [20].

These demographic details show that compared to those not reporting allergy, respondents who reported suffering from allergies were younger, with an over-representation of women and fair skin phototypes.

\subsection{Allergy Population}

The estimated prevalence of the different allergies and skin reactions are described in Table 2.

Table 2. Type of allergies and skin reaction potential.

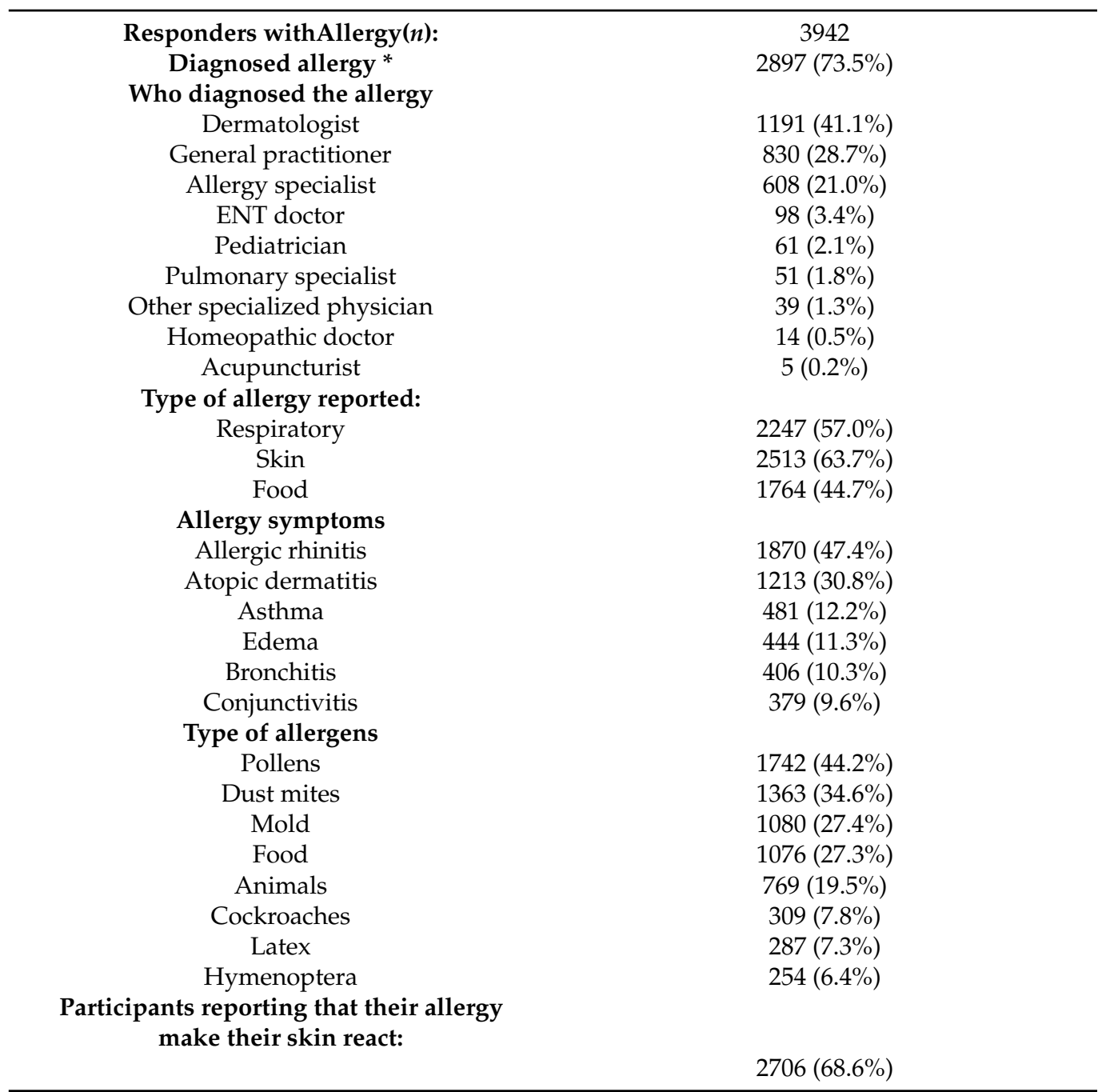

The proportion of allergy-reporting respondents declaring that their allergy makes their skin react was high $(68.6 \%)$. The incidence of various types of skin reactions in individuals reporting, or not, various types of allergy was evaluated (Table 3). 
Table 3. Allergy and skin reactions.

\begin{tabular}{cccc}
\hline & No Diagnosed Allergy & Diagnosed Allergy & $\begin{array}{c}\text { RR } \\
(\boldsymbol{p} \text {-Value })\end{array}$ \\
\hline Acne & $1664(21.0 \%)$ & $919(32.4 \%)$ & $1.54(<0.001)$ \\
Contact eczema & $498(6.4 \%)$ & $641(23.5 \%)$ & $3.68(<0.001)$ \\
Atopic dermatitis & $710(9.2 \%)$ & $824(30.4 \%)$ & $3.3(<0.001)$ \\
Rosacea & $520(6.7 \%)$ & $450(16.5 \%)$ & $2.45(<0.001)$ \\
Psoriasis & $413(5.3 \%)$ & $329(11.8 \%)$ & $2.25(<0.001)$ \\
Vitiligo & $133(1.7 \%)$ & $156(5.7 \%)$ & $3.3(<0.001)$ \\
Seborrheic & $697(9.0 \%)$ & $582(21.5 \%)$ & $2.38(<0.001)$ \\
dermatitis & & & \\
\hline
\end{tabular}

A significant increase of all types of skin reactions in the presence of reported allergy was observed. Therefore, the incidence of skin discomforts on respondents with at least one described skin reaction was investigated (Table 4). Pruritus, burning sensations, and pain were significantly associated with skin reactions.

Table 4. Skin reactions and discomfort sensations.

\begin{tabular}{cccc}
\hline & $\begin{array}{c}\text { No Skin Reaction } \\
\mathbf{6 0 3 9}(\mathbf{5 4 . 6 \% )}\end{array}$ & $\begin{array}{c}\text { Skin Reactions } \\
\mathbf{5 0 2 8}(\mathbf{4 5 . 4} \%)\end{array}$ & $\begin{array}{c}\text { RR } \\
(\boldsymbol{p} \text {-Value) }\end{array}$ \\
\hline Itching & $1789(29.6 \%)$ & $2793(55.5 \%)$ & $1.88(<0.001)$ \\
Burning & $1043(17.3 \%)$ & $1700(33.8 \%)$ & $1.96(<0.001)$ \\
Pain & $1123(18.6 \%)$ & $1609(32.0 \%)$ & $1.72(<0.001)$ \\
\hline
\end{tabular}

Next, an increased risk of QoL alteration was investigated in patients with or without skin discomforts. The risk of QoL impairment was increased in the presence of skin discomforts like pain and burning. For pruritus, even if the comparisons of some attributes are not statistically significant, the effect size remains relatively high (Table 5).

Table 5. Skin discomfort and impact on the quality of life.

\begin{tabular}{|c|c|c|c|}
\hline & $\begin{array}{c}\text { With Skin } \\
\text { Discomfort } \\
n(\%)\end{array}$ & $\begin{array}{c}\text { Without Skin } \\
\text { Discomfort } \\
n(\%)\end{array}$ & $\mathbf{R} \mathbf{R}(p$-Value $)$ \\
\hline Pain $(n)$ & 138 & 68 & \\
\hline Fatigue & $30(21.7 \%)$ & $28(41.2 \%)$ & $1.89(0.005)$ \\
\hline Embarrassment & $48(34.8 \%)$ & $35(51.5 \%)$ & $1.48(0.024)$ \\
\hline Anxiety & $25(18.1 \%)$ & $28(41.2 \%)$ & $2.27(<0.001)$ \\
\hline Difficulties with day-to-day management & $13(9.4 \%)$ & $23(33.8 \%)$ & $3.59(<0.001)$ \\
\hline Altered quality of sleep & $25(18.1 \%)$ & $30(44.1 \%)$ & $2.44(<0.001)$ \\
\hline Burning $(n)$ & 66 & 140 & \\
\hline Fatigue & $29(20.7 \%)$ & $29(43.9 \%)$ & $2.12(<0.001)$ \\
\hline Embarrassment & $43(30.7 \%)$ & $40(60.6 \%)$ & $1.97(<0.001)$ \\
\hline Anxiety & $24(17.1 \%)$ & $29(43.9 \%)$ & $2.56(<0.001)$ \\
\hline Difficulties with day-to-day management & $13(9.3 \%)$ & $23(34.8 \%)$ & $3.75(<0.001)$ \\
\hline Altered quality of sleep & $22(15.7 \%)$ & $33(50.0 \%)$ & $3.18(<0.001)$ \\
\hline Itching $(n)$ & 104 & 102 & \\
\hline Fatigue & $24(23.1 \%)$ & $34(33.3 \%)$ & $1.44(0.122)$ \\
\hline Embarrassment & $35(33.7 \%)$ & $48(47.1 \%)$ & $1.4(0.065)$ \\
\hline Anxiety & $18(17.3 \%)$ & $35(34.3 \%)$ & $1.98(0.007)$ \\
\hline Difficulties with day-to-day management & $11(10.6 \%)$ & $25(24.5 \%)$ & $2.32(0.01)$ \\
\hline Altered quality of sleep & $18(17.3 \%)$ & $37(36.3 \%)$ & $2.1(0.003)$ \\
\hline
\end{tabular}

\section{Discussion}

In this self-reported survey on the representative adult population of five major countries, $35.6 \%$ of respondents reported having allergies, with symptoms such as allergic rhinitis, atopic dermatitis, asthma, edema, bronchitis, and conjunctivitis. One can extrapolate from these data that they were predominantly fair-skinned women, younger than those responders reporting no allergy. This proportion is similar to those reported in previous studies $[17,21]$. In most cases $(73.5 \%)$, the reported allergies were diagnosed by a physician. 
Among individuals reporting allergies, $68.6 \%$ declared that their allergy makes their skin react. The prevalence of skin reactions of various types were measured: acne, contact eczema, atopic dermatitis, rosacea, psoriasis, vitiligo, or seborrheic dermatitis. Interestingly, an increase of all types of skin reactions was observed in the presence of reported allergy. These skin reactions were most often associated with skin discomforts such as itching, burning, and pain. Skin discomfort was associated with QoL alterations such as fatigue, embarrassment, anxiety, difficulties with day-to-day management, and altered quality of sleep.

The role of the skin barrier in allergic sensitization has been well-described [16]. Skin, as the first frontier between the body and the environment, is a potential route of allergen penetration and plays a predominant role in the development of allergies. An intact epidermal barrier protects from exposure to exogenous allergens, whereas physical or functional impairment of the skin barrier promotes sensitization [22].

The present study, conducted on a large and ethnically heterogeneous population of industrialized and developing countries, highlights the fact that the perception of skin aggression is generalized. Indeed, even in the absence of diagnosed allergy or allergic symptoms, the likelihood of individuals presenting with "dry", "sensitive" or "fragile" skin is increasing, and those individuals are prone to experience skin reactions similar to those described in the present report. In this study, the actual presence or absence of existing allergies could not be verified.

Another aspect that the present study points to is the important role of the skin barrier -reinforcing the importance of topical treatments, capable of improving skin defenses without introducing potentially allergenic components. In this context, the role of the skin microbiota should also be raised. Indeed, the skin is an ecological niche for a wide range of microorganisms, which are, in their majority, harmless or beneficial, providing protection against pathogens and playing a role in modulating the cutaneous innate and adaptive immune systems [23]. Some bacteria can provide protection against inflammation, while others may cause a long-lasting cutaneous inflammation [24-26].

Dysbiosis, or disruption of balance in the microbiome, has been extensively studied in the context of atopic dermatitis, the first step of the "atopic march", which can subsequently lead to allergic rhinitis and asthma [27]. Moreover, since the skin microbiota is under the influence of the skin water content [28], the importance of skin moisturizers for the maintenance of the skin barrier and of the well-balanced skin microbiome through a targeted bacteria inhibition and a prebiotic activity has been highlighted [29].

The reported presence of allergies and skin reactions with no explicit validation by an independent medical staff may be one limitation of this study. Indeed, survey participants can misinterpret allergy and/or cutaneous symptoms, e.g., an adverse effect of food intake, and without the medically proven evidence of immune mechanism, the self-observed symptoms may easily be mistaken to be an allergic reaction and/or a skin reaction and reported as such [30]. Another limitation of this approach is that only adults of 18 years old and older were sampled, whereas allergy rates are increasing most rapidly among children [5]. Nevertheless, it is hardly conceivable to perform a reliable questionnaire survey via e-mail concerning QoL in toddlers.

\section{Conclusions}

Quantifying the prevalence and the association of allergies, skin reactions, and discomfort sensations with their ultimate social impact translated from quality of life alterations, is critical for diseases like allergies as they affect a growing population in industrialized and developed countries. Several environmental factors can interfere with the skin barrier function and the skin microbiota. Daily use of topical treatments, such as moisturizers, aiming at the reinforcement of the skin barrier and/or balancing the skin microbiome, should help prevent allergic skin reaction in individuals with an altered skin barrier. Such relief of discomfort feelings could contribute to a better quality of life. 
Supplementary Materials: The following are available online at https://www.mdpi.com/article/10 .3390/ijerph18094501/s1, S1: Subset of the survey questionnaire.

Author Contributions: Conceptualization, M.H., S.S., C.T. and A.L.D.; methodology: M.H., S.S., C.T. and A.L.D.; project administration, M.H., S.S., C.T. and A.L.D.; resources: M.H., S.S., C.T. and A.L.D.; validation, M.H., S.S., C.T. and A.L.D.; writing-original draft: M.H., S.S., C.T. and A.L.D.; writing-review and editing, M.H., S.S., C.T. and A.L.D. All authors have read and agreed to the published version of the manuscript.

Funding: This work was supported by La Roche-Posay Dermatological Laboratories, France.

Institutional Review Board Statement: No need for an institutional review board submission as the collected data was completely anonymized without involving direct patient contact and with no possibility of re-identification.

Informed Consent Statement: Informed consent was obtained from all subjects involved in the study.

Acknowledgments: The authors acknowledge Mathieu C. Tamby, from Elixience LLC, Paris, France, for his help copywriting this manuscript.

Conflicts of Interest: The authors declare no conflict of interest.

\section{References}

1. Masoli, M.; Fabian, D.; Holt, S.; Beasley, R. Global Initiative for Asthma (GINA) Program. The global burden of asthma: Executive summary of the GINA Dissemination Committee report. Allergy 2004, 59, 469-478. [CrossRef]

2. Araujo, J.A. Particulate air pollution, systemic oxidative stress, inflammation, and atherosclerosis. Air Qual. Atmos. Health 2010, 4, 79-93. [CrossRef]

3. Osborne, N.J.; Koplin, J.J.; Martin, P.E.; Gurrin, L.C.; Lowe, A.J.; Matheson, M.C.; Ponsonby, A.L.; Wake, M.; Tang, M.L.; Dharmage, S.C.; et al. Prevalence of challenge-proven IgE-mediated food allergy using population-based sampling and predetermined challenge criteria in infants. J. Allergy Clin. Immunol. 2011, 127, 668-676.e1-2. [CrossRef]

4. Sicherer, S.H.; Sampson, H.A. Food allergy: A review and update on epidemiology, pathogenesis, diagnosis, prevention, and management. J. Allergy Clin. Immunol. 2018, 141, 41-58. [CrossRef]

5. Jackson, K.D.; Howie, L.D.; Akinbami, L.J. Trends in allergic conditions among children: United States, 1997-2011. NCHS Data Brief. 2013, 121, 1-8.

6. Burks, W. Skin manifestations of food allergy. Pediatrics 2003, 111 (Suppl. 3), 1617-1624. [PubMed]

7. Fasano, M.B. Dermatologic food allergy. Pediatr. Ann. 2006, 35, 727-731. [CrossRef] [PubMed]

8. Oehling, A.; Fernandez, M.; Cordoba, H.; Sanz, M.L. Skin manifestations and immunological parameters in childhood food allergy. J. Investig. Allergol. Clin. Immunol. 1997, 7, 155-159.

9. Meltzer, E.O. Allergic Rhinitis: Burden of Illness, Quality of Life, Comorbidities, and Control. Immunol. Allergy Clin. N. Am. 2016, 36, 235-248. [CrossRef] [PubMed]

10. Silverberg, J.I.; Gelfand, J.M.; Margolis, D.J.; Boguniewicz, M.; Fonacier, L.; Grayson, M.H.; Simpson, E.L.; Ong, P.Y.; Chiesa Fuxench, Z.C. Patient burden and quality of life in atopic dermatitis in US adults: A population-based cross-sectional study. Ann. Allergy Asthma Immunol. 2018, 121, 340-347. [CrossRef]

11. Schonmann, Y.; Mansfield, K.E.; Hayes, J.F.; Abuabara, K.; Roberts, A.; Smeeth, L.; Langan, S.M. Atopic Eczema in Adulthood and Risk of Depression and Anxiety: A Population-Based Cohort Study. J. Allergy Clin. Immunol. Pr. 2020, 8, 248-257.e16. [CrossRef]

12. Cappuccio, A.; Limonta, T.; Parodi, A.; Cristaudo, A.; Bugliaro, F.; Cannavo, S.P.; Rossi, O.; Gurioli, C.; Vignoli, A.; Parente, R.; et al. Living with Chronic Spontaneous Urticaria in Italy: A Narrative Medicine Project to Improve the Pathway of Patient Care. Acta Derm. Venereol. 2017, 97, 81-85. [CrossRef]

13. Ayala, F.; Nino, M.; Fabbrocini, G.; Panariello, L.; Balato, N.; Foti, C.; Tosti, A.; Corazza, M.; Valsecchi, R.H.; Gola, M.; et al. Quality of life and contact dermatitis: A disease-specific questionnaire. Dermatitis 2010, 21, 84-90. [CrossRef] [PubMed]

14. Lack, G.; Fox, D.; Northstone, K.; Golding, J.; Avon Longitudinal Study of Parents; Children Study Team. Factors associated with the development of peanut allergy in childhood. N. Engl. J. Med. 2003, 348, 977-985. [CrossRef]

15. Rodriguez-Martinez, C.E.; Sossa-Briceno, M.P.; Castro-Rodriguez, J.A. Factors predicting persistence of early wheezing through childhood and adolescence: A systematic review of the literature. J. Asthma Allergy 2017, 10, 83-98. [CrossRef] [PubMed]

16. Proksch, E.; Brasch, J. Abnormal epidermal barrier in the pathogenesis of contact dermatitis. Clin. Derm. 2012, 30, 335-344. [CrossRef]

17. Seite, S.; Kuo, A.M.; Taieb, C.; Strugar, T.L.; Lio, P. Self-Reported Prevalence of Allergies in the USA and Impact on Skin-An Epidemiological Study on a Representative Sample of American Adults. Int. J. Environ. Res. Public Health 2020, $17,3360$. [CrossRef] [PubMed]

18. Seite, S.; Taieb, C.; Lazic Strugar, T.; Lio, P.; Bobrova, E.E. Self-reported allergies in Russia and impact on skin. Sage Open Med. 2020, 8, 2050312120957916. [CrossRef] [PubMed] 
19. Rona, R.J.; Vargas, C.; Vianna, E.O.; Bustos, P.; Bettiol, H.; Amigo, H.; Mackenney, J.; Barbieri, M.A. Impact of specific sensitization on asthma and rhinitis in young Brazilian and Chilean adults. Clin. Exp. Allergy 2008, 38, 1778-1786. [CrossRef] [PubMed]

20. Fitzpatrick, T.B. The validity and practicality of sun-reactive skin types I through VI. Arch. Derm. 1988, 124, 869-871. [CrossRef]

21. Papadopoulos, N.G.; Agache, I.; Bavbek, S.; Bilo, B.M.; Braido, F.; Cardona, V.; Custovic, A.; Demonchy, J.; Demoly, P.; Eigenmann, P.; et al. Research needs in allergy: An EAACI position paper, in collaboration with EFA. Clin. Transl. Allergy $2012,2,21$. [CrossRef] [PubMed]

22. Egawa, G.; Kabashima, K. Barrier dysfunction in the skin allergy. Allergol. Int. 2018, 67, 3-11. [CrossRef]

23. Salava, A.; Lauerma, A. Role of the skin microbiome in atopic dermatitis. Clin. Transl. Allergy 2014, 4, 33. [CrossRef] [PubMed]

24. Chau, T.A.; McCully, M.L.; Brintnell, W.; An, G.; Kasper, K.J.; Vines, E.D.; Kubes, P.; Haeryfar, S.M.; McCormick, J.K.; Cairns, E.; et al. Toll-like receptor 2 ligands on the staphylococcal cell wall downregulate superantigen-induced T cell activation and prevent toxic shock syndrome. Nat. Med. 2009, 15, 641-648. [CrossRef] [PubMed]

25. Lai, Y.; Di Nardo, A.; Nakatsuji, T.; Leichtle, A.; Yang, Y.; Cogen, A.L.; Wu, Z.R.; Hooper, L.V.; Schmidt, R.R.; von Aulock, S.; et al. Commensal bacteria regulate Toll-like receptor 3-dependent inflammation after skin injury. Nat. Med. 2009, 15, 1377-1382. [CrossRef]

26. Biedermann, T.; Skabytska, Y.; Kaesler, S.; Volz, T. Regulation of T Cell Immunity in Atopic Dermatitis by Microbes: The Yin and Yang of Cutaneous Inflammation. Front. Immunol. 2015, 6, 353. [CrossRef]

27. Seite, S.; Bieber, T. Barrier function and microbiotic dysbiosis in atopic dermatitis. Clin. Cosmet. Investig. Derm. 2015, 8, 479-483. [CrossRef] [PubMed]

28. Stevenson, A.; Cray, J.A.; Williams, J.P.; Santos, R.; Sahay, R.; Neuenkirchen, N.; McClure, C.D.; Grant, I.R.; Houghton, J.D.; Quinn, J.P.; et al. Is there a common water-activity limit for the three domains of life? ISME J. 2015, 9, 1333-1351. [CrossRef]

29. Baldwin, H.E.; Bhatia, N.D.; Friedman, A.; Eng, R.M.; Seite, S. The Role of Cutaneous Microbiota Harmony in Maintaining a Functional Skin Barrier. J. Drugs Derm. 2017, 16, 12-18. [CrossRef]

30. Sicherer, S.H. Epidemiology of food allergy. J. Allergy Clin. Immunol. 2011, 127, 594-602. [CrossRef] [PubMed] 